\title{
Enthusiasm for cancer screening in Great Britain: a general population survey
}

Updated online 26 May 2016: This article was originally published under a CC BY-NC-SA 4.0 license, but has now been made available under a CC BY 4.0 license. The PDF and HTML versions of the paper have been modified accordingly

\author{
J Waller ${ }^{*}, 1$, K Osborne $^{2}$ and J Wardle ${ }^{1}$ \\ ${ }^{1}$ Health Behaviour Research Centre, Department of Epidemiology and Public Health, University College London, Gower Street, \\ London WC1E 6BT, UK and ${ }^{2}$ Cancer Research UK, Angel Building, 407 St John Street, London EC1V 4AD, UK
}

Background: With growing concerns about risk of harm from cancer screening, particularly from overdiagnosis, this study aimed to assess public attitudes to cancer screening in Great Britain.

Methods: We used a population-based survey to assess attitudes to cancer screening, screening history and demographic characteristics, in men and women aged 50-80 years. Data were collected using face-to-face computer-assisted interviews in 2012.

Results: In our sample of 2024, attitudes to cancer screening were overwhelmingly positive with almost $90 \%$ believing that screening is 'almost always a good idea' and $49 \%$ saying they would be tested for cancer even if it was untreatable. Attitudes were particularly positive among those who had previously taken part in breast or colorectal screening.

Conclusions: Our findings suggest that attitudes to cancer screening are very positive in Great Britain. Widespread enthusiasm for cancer screening may hamper attempts to encourage a greater appreciation of the limitations and potential harms of screening.

Provision of information about cancer screening has been the subject of much debate in recent years, particularly in relation to mammography where it has been argued that the risks are downplayed (Jørgensen and Gøtzsche, 2006; Gøtzsche et al, 2009). In the United Kingdom, information materials for all three national cancer screening programmes (breast, cervical and colorectal) have recently been revised, with the aim of providing balanced information to allow people to make an informed choice about participation (Richards, 2011). The underlying model is 'consider an offer' (Entwistle et al, 2008), with a clear National Health Service (NHS) recommendation, but also direct advice to make an individual decision (Informed Choice about Cancer Screening, 2014). However, people's screening decisions are also likely to be influenced by prevailing public attitudes and, in some cases, their own past behaviour.

A population survey carried out in the United States in 20012002 found very high levels of enthusiasm for cancer screening (Schwartz et al, 2004). They speculated that this could be due to pervasive marketing of screening and a public discourse in which the limitations of screening are rarely discussed. However, it could also be a consequence of the intuitive appeal of 'catching cancer early'. Although such enthusiasm may promote screening uptake, it can also lead to dissatisfaction when guidelines are revised to reduce the recommended frequency or age range for screening (Squiers et al, 2011; Arkes and Gaissmaier, 2012). It may also hamper efforts to implement an informed choice approach because potential participants see no reason to revisit an 'obvious' choice.

Cancer screening in Great Britain takes place in a different context from the United States. Direct-to-consumer marketing is uncommon, there are few national public health campaigns on screening, and primary-care physicians have little involvement in programme delivery (particularly for colorectal screening). Screening is offered using organised call-recall programmes, in which routine invitations are sent to all age-eligible adults alongside information on risks and benefits. The public in Great Britain has also recently been exposed to media debate about the risks and benefits of breast screening, including considerable

*Correspondence: Dr J Waller; E-mail: j.waller@ucl.ac.uk

Received 10 July 2014; revised 27 November 2014; accepted 1 December 2014;

published online 23 December 2014

(c) 2015 Cancer Research UK. All rights reserved 0007-0920/15

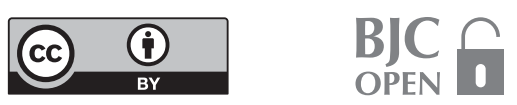


publicity surrounding a review of the mammography programme (Richards, 2011). We assessed enthusiasm for cancer screening in this context; hypothesising that attitudes in the Great Britain might be less positive than in the United States 10 years earlier.

\section{METHODS}

We commissioned a survey on attitudes to cancer screening in spring 2012 as part of TNS International's regular omnibus survey (TNS International is the name of the research agency we commissioned to carry out the fieldwork for this study). This is a weekly, population-based, face-to-face survey, in which clients can commission questions. Sampling points across England, Scotland and Wales are selected using random location sampling, stratified by region and social grade. Local quotas are used to balance the sample of adults interviewed at eligible addresses and to adjust for likelihood of being at home. Quotas are set for gender (male/female housewife/ female non-housewife), work status and presence of children. The survey uses home-based, computer-assisted, personal interviews.

Participants. Adults aged 50-80 years were eligible. All women in this age-group would have been offered breast screening. Since 1988, women aged 50-70 years have been invited for mammography every 3 years, and the programme is currently being extended to ages 47-49 and 71-73. Both men and women would have been around the age of eligibility for colorectal screening. People aged 60-69 years have been offered biennial screening with faecal occult blood testing since 2006 (with slight variations in age-ranges between the England, Scotland and Wales), and onceonly flexible sigmoidoscopy screening is currently being implemented at age 55 years (since 2013).

Measures. We included items from the earlier US survey (Schwartz et al, 2004) to assess enthusiasm for screening (see Table 1 for item wording). We also asked participants whether they had ever been screened for breast or colorectal cancer and collected demographic information.

Analyses. Analyses were carried out using PASW Statistics 18.0 (SPSS Inc., 2009). Weights provided by TNS were applied to the data in all analyses to adjust the sample to be populationrepresentative with respect to age, gender, social class and geographical region. Logistic regression analyses were used to calculate adjusted odds ratios for endorsement of each screening attitude by demographic characteristic and screening participation.

\section{RESULTS}

Sample characteristics. The overall weighted sample size was 1895 ( $51 \%, n=975$ women). Mean age was 63.0 (s.d. = 8.6), most participants were married (60\%), and white (94\%), and $39 \%$ had no educational qualifications (Appendix 1). Among those who were age-eligible for screening at the time of the survey, $62 \%$ had already had colorectal cancer (CRC) screening (58\% of men and $66 \%$ of women) and $86 \%$ of women had attended breast screening.

Overall beliefs. Enthusiasm for screening was extremely high (Table 1). Nearly $90 \%$ of respondents agreed that screening is 'almost always a good idea', 75\% believed that earlier detection means treatment can save lives 'most' or 'all' the time, and $64 \%$ thought early diagnosis means less treatment is needed 'most' or 'all' the time. Around half (49\%) were previously unaware that some cancers are slow-growing and unlikely to cause problems, but $45 \%$ of the total sample wanted to be tested for such a cancer. A similar proportion (49\%) wanted to be tested for a cancer for
Table 1. Enthusiasm for screening

\begin{tabular}{|c|c|c|}
\hline Item & Response & $N(\%)$ \\
\hline \multirow{3}{*}{$\begin{array}{l}\text { Do you think routine cancer screening tests for } \\
\text { healthy people are almost always a good idea? }\end{array}$} & Yes & $1682(88.8)$ \\
\hline & No & $137(7.3)$ \\
\hline & Do not know & $75(4.0)$ \\
\hline \multirow{4}{*}{$\begin{array}{l}\text { How often does finding cancer early mean that } \\
\text { treatment saves lives? }\end{array}$} & None & $19(1.0)$ \\
\hline & Some & $462(24.4)$ \\
\hline & Most & 982 (51.8) \\
\hline & All the time & $432(22.8)$ \\
\hline \multirow{4}{*}{$\begin{array}{l}\text { How often does finding cancer early mean that } \\
\text { a person can have less treatment? }\end{array}$} & None & $50(2.6)$ \\
\hline & Some & $630(33.2)$ \\
\hline & Most & 915 (48.3) \\
\hline & All the time & 301 (15.9) \\
\hline \multirow{3}{*}{$\begin{array}{l}\text { Have you ever heard of cancers that grow so } \\
\text { slowly that they are unlikely to cause you any } \\
\text { problems in your lifetime? }\end{array}$} & Yes & $873(46.1)$ \\
\hline & No & $929(49.0)$ \\
\hline & Do not know & $92(4.9)$ \\
\hline \multirow{3}{*}{$\begin{array}{l}\text { Would you want to be tested to see if you had a } \\
\text { slow-growing cancer like that? }\end{array}$} & Yes & $861(45.4)$ \\
\hline & No & $876(46.2)$ \\
\hline & Do not know & $158(8.3)$ \\
\hline \multirow{3}{*}{$\begin{array}{l}\text { If there was a kind of cancer for which nothing } \\
\text { could be done, would you want to be tested to } \\
\text { see if you had it? }\end{array}$} & Yes & 931 (49.1) \\
\hline & No & 774 (40.8) \\
\hline & Do not know & $190(10.1)$ \\
\hline \multirow{3}{*}{$\begin{array}{l}\text { In the past, do you think you have had too many } \\
\text { screening tests for cancer, too few or about the } \\
\text { right number }\end{array}$} & Too few & 504 (26.6) \\
\hline & About right & $1360(71.8)$ \\
\hline & Too many & $31(1.6)$ \\
\hline \multirow{3}{*}{$\begin{array}{l}\text { Do you feel that someone [who] does not go for } \\
\text { screening is irresponsible? }\end{array}$} & Yes & $1112(58.7)$ \\
\hline & No & 624 (32.9) \\
\hline & Do not know & $159(8.4)$ \\
\hline
\end{tabular}

which nothing could be done. Almost $60 \%$ regarded declining a screening offer as 'irresponsible', and $72 \%$ believed they had received the right number of screening tests in the past.

Demographic variations in beliefs. In adjusted analyses (see Table 2), the oldest age group were less likely to believe that finding cancer early means that treatment saves lives (odds ratio $(\mathrm{OR})=0.67,95 \%$ confidence interval $(\mathrm{CI}): 0.51-0.89)$ and was less likely than the younger age group to believe they had too few screening tests in the past (see Table 2). Men were more likely than women to want to be tested for an incurable cancer $(\mathrm{OR}=1.32,95 \% \mathrm{CI}: 1.08-1.61)$ or for a slow-growing cancer $(\mathrm{OR}=1.29,95 \% \mathrm{CI}: 1.06-1.57)$ and were also more likely to think they had received too few screening tests in the past $(\mathrm{OR}=2.82$, 95\% CI: 2.26-3.54). Men were less likely to have heard of a slowgrowing cancer $(\mathrm{OR}=0.72,95 \% \mathrm{CI}$ : 0.59-0.88). Participants with no educational qualifications were more likely to think that screening non-attendance is irresponsible $(\mathrm{OR}=1.26,95 \% \mathrm{CI}$ : $1.02-1.56)$ but less likely to have heard of a slow-growing cancer $(\mathrm{OR}=0.47,95 \% \mathrm{CI}: 0.38-0.57)$. Those of non-white ethnicity were less likely to believe screening is a good idea $(\mathrm{OR}=0.27,95 \% \mathrm{CI}$ : $0.15-0.50)$ and that screening non-attendance is irresponsible $(\mathrm{OR}=0.56,95 \% \mathrm{CI}: 0.34-0.91)$. Those who were not married were less likely to be aware of a slow-growing cancer $(\mathrm{OR}=0.77,95 \%$ CI: 0.63-0.94).

Associations between beliefs and previous screening attendance. After controlling for demographic variables, non-participation in CRC screening was associated with less positive beliefs about the benefits of screening, lower awareness of slow-growing cancers, less enthusiasm for being tested for untreatable or slow-growing cancers, lower odds of believing that non-attendance is irresponsible and higher odds of believing that one has had too few screening tests in the past (see Table 2). 
Table 2. Associations between screening beliefs, demographic factors and screening experience

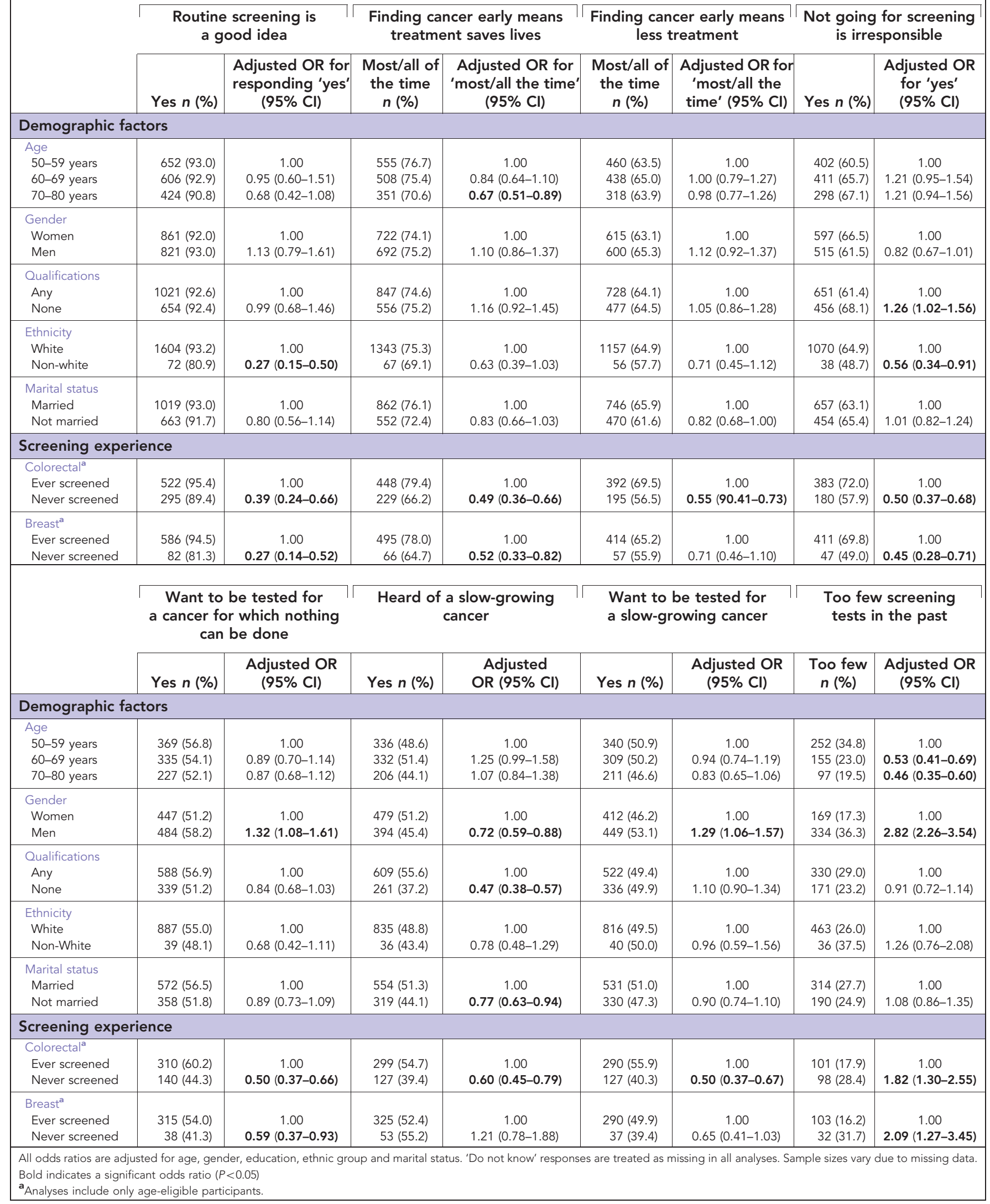

A similar pattern of findings was observed for breast screening, but there was no association between previous attendance and either awareness of, or desire to be tested for, a slow-growing cancer. The association with the belief that finding cancer early means less treatment was also nonsignificant. 


\section{DISCUSSION}

Our findings suggest that enthusiasm for cancer screening in Great Britain in 2012 is at least as high as in the United States 10 years earlier (Schwartz et al, 2004). The association between past screening attendance and enthusiasm was not universal and was, to some extent, programme-specific. It is striking that enthusiasm was so high despite screening participation (in this sample and in the wider UK population) being considerably lower $-54 \%$ for CRC screening nationally (von Wagner et al, 2011). This is consistent with the idea that, although people might 'know' that screening is a good idea, they may hold contradictory beliefs or not get round to participating.

Men's greater enthusiasm for being tested for slow-growing and incurable cancers may be the result of lower exposure to screening and less familiarity with issues of overdiagnosis. This, together with their belief that they have had too few screening tests, is consistent with positive attitudes to prostate specific antigen (PSA) testing in men (Chapple et al, 2008). This is a key area for future investigation.

The similarity in attitudes in Great Britain and the United States raises the possibility that positive appraisal of screening is less due to marketing and public health campaigns (as Schwartz et al (2004) suggest), because both are less pervasive in Britain, but arises from a lay logic that earlier interception of the oncogenic process is beneficial, perhaps reinforced by public discourse around the value of prevention and early diagnosis. In addition, the fact that many respondents in both countries would want to know about an untreatable cancer suggests that knowledge of health status per se is valued. Taken together, these results highlight the challenge of communicating the benefit/harm balance of any particular screening modality (see for example, Brawley et al, 2011) and suggest that the public is probably relatively unresponsive to media debate on overdiagnosis.

The study has a number of limitations, the most important of which is that TNS International are not able to supply information on response rate. Although weighting the data goes some way to adjusting for non-response bias, the generalisability of the findings is uncertain given the unknown response rate.

Medical concerns about an 'epidemic' of overdiagnosis (Hoffman and Cooper, 2012) will be hard to communicate in the presence of such enthusiasm. Positive attitudes towards screening may make participation a reflexive process, inhibiting a 'rational' appraisal of risk/benefit information. These findings indicate the need for further work to explore ways of encouraging active engagement with screening decisions.

\section{ACKNOWLEDGEMENTS}

The survey was carried out by TNS International as part of their regular omnibus survey. This survey was supported by funding from Cancer Research UK.

\section{CONFLICT OF INTEREST}

The authors declare no conflict of interest.

\section{ETHICAL APPROVAL}

The study was exempt from the need for ethical approval under the terms of the UCL Research Ethics Committee that does not require approval for 'research involving the use of non-sensitive, completely anonymous educational tests, survey and interview procedures when the participants are not defined as 'vulnerable' and participation will not induce undue psychological stress or anxiety'.

\section{REFERENCES}

Informed Choice about Cancer Screening (2014) http://www. informedchoiceaboutcancerscreening.org/ (accessed 5 March 2014).

Arkes HR, Gaissmaier W (2012) Psychological research and the prostatecancer screening controversy. Psychol Sci 23(6): 547-553.

Brawley O, Byers T, Chen A, Pignone M, Ransohoff D, Schenk M, Smith R, Sox H, Thorson AG, Wender R (2011) New American Cancer Society process for creating trustworthy cancer screening guidelines. JAMA 306(22): 2495-2499.

Chapple A, Ziebland S, Hewitson P, McPherson A (2008) Why men in the United Kingdom still want the prostate specific antigen test. Qual Health Res 18(1): 56-64.

Entwistle VA, Carter SM, Trevena L, Flitcroft K, Irwig L, McCafferty K, Salked G (2008) Communicating about screening. BMJ 337: 789-791.

Gøtzsche PC, Hartling OJ, Nielsen M, Brodersen J, Jørgensen KJ (2009) Breast screening: the facts-or maybe not. BMJ 338: 446-448.

Hoffman JR, Cooper RJ (2012) Overdiagnosis of disease: a modern epidemic. Arch Intern Med 172(15): 1123-1124.

Jørgensen KJ, Gøtzsche PC (2006) Content of invitations for publicly funded screening mammography. BMJ 332(7540): 538-541.

Richards M (2011) An independent review is under way. BMJ 343: d6843.

Schwartz LM, Woloshin S, Fowler Jr. FJ, Welch HG (2004) Enthusiasm for cancer screening in the United States. JAMA 291(1): 71-78.

SPSS Inc. (2009) Released 2009. PASW Statistics for Windows, Version 18.0. SPSS Inc.: Chicago.

Squiers LB, Holden DJ, Dolina SE, Kim AE, Bann CM, Renaud JM (2011) The public's response to the U.S. Preventive Services Task Force's 2009 recommendations on mammography screening. Am J Prev Med 40(5): 497-504.

von Wagner C, Baio G, Raine R, Snowball J, Morris S, Atkin W, Obichere A, Handley G, Logan RF, Rainbow S, Smith S, Halloran S, Wardle J (2011) Inequalities in participation in an organized national colorectal cancer screening programme: results from the first 2.6 million invitations in England. Int J Epidemiol 40(3): 712-718.

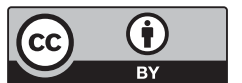

This work is licensed under the Creative Commons Attribution 4.0 International License. To view a copy of this license, visit http://creativecommons.org/licenses/by/4.0/ 


\section{APPENDIX 1}

\section{Appendix 1. Sample characteristics}

\begin{tabular}{|c|c|c|}
\hline & $\begin{array}{c}N(\%) \\
\text { unweighted }\end{array}$ & $\begin{array}{c}N(\%) \text { With } \\
\text { weights applied }^{\text {a }}\end{array}$ \\
\hline All & 2024 & 1895 \\
\hline \multicolumn{3}{|l|}{ Gender } \\
\hline Male & $951(47.0)$ & $920(48.5)$ \\
\hline Female & $1073(53.0)$ & $975(51.5)$ \\
\hline \multicolumn{3}{|l|}{ Age group } \\
\hline $50-59$ years & $658(32.5)$ & $724(38.2)$ \\
\hline $60-69$ years & $723(35.7)$ & $674(35.6)$ \\
\hline $70-80$ years & $643(31.8)$ & $498(26.3)$ \\
\hline \multicolumn{3}{|l|}{ Marital status } \\
\hline Married & $1167(57.7)$ & $1132(59.8)$ \\
\hline Single/separated/widowed/divorced & $857(42.3)$ & $763(40.2)$ \\
\hline \multicolumn{3}{|l|}{ Ethnicity } \\
\hline White & $1914(94.6)$ & $1784(94.1)$ \\
\hline Non-white & $96(4.7)$ & $97(5.1)$ \\
\hline \multicolumn{3}{|l|}{ Educational qualifications } \\
\hline None & $871(43.0)$ & $738(39.0)$ \\
\hline Any educational qualifications & $1132(57.0)$ & $1136(60.6)$ \\
\hline \multicolumn{3}{|c|}{ Colorectal screening history $(n=1028)$} \\
\hline Eligible and ever attended & $636(61.9)$ & $564(62.0)$ \\
\hline Eligible and never attended & $392(38.1)$ & $345(38.0)$ \\
\hline \multicolumn{3}{|l|}{ Breast screening history $(n=777)$} \\
\hline Eligible and ever attended & $666(85.7)$ & $635(86.2)$ \\
\hline Eligible and never attended & $111(14.2)$ & $101(13.8)$ \\
\hline \multicolumn{3}{|c|}{$\begin{array}{l}\text { aWeights are used to adjust the sample to be representative of the wider population of } \\
\text { Great Britain with respect to gender, age, social class and geographical region. As weights } \\
\text { may be }<1 \text {, the overall sample size is reduced when weights are applied. }\end{array}$} \\
\hline
\end{tabular}

